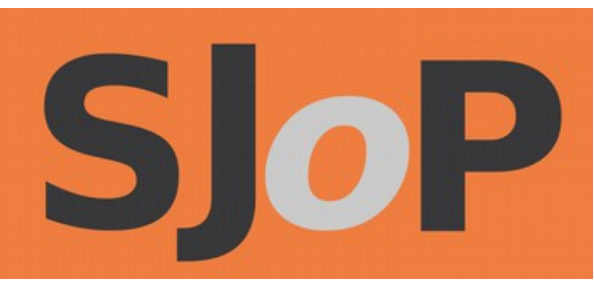

\title{
'I'm not really a clown': critical reflection on a Clown Cabaret Scratch Night
}

\section{LUCY AMSDEN}

The Scottish Journal of Performance

Volume 2, Issue 2; June 2015

ISSN: 2054-1953 (Print) / ISSN: 2054-1961 (Online)

Publication details: http://www.scottishjournalofperformance.org

To cite this article: Amsden, L., 2015. 'I'm not really a clown': critical reflection on a Clown Cabaret Scratch Night. Scottish Journal of

Performance, 2(2): pp.11-32.

To link to this article: http://dx.doi.org/10.14439/sjop.2015.0202.02

CC This work is licensed under a Creative Commons
Attribution 4.0 International License. See
http://creativecommons.org/licenses/by/4.0/ for details. 


\title{
'I'm not really a clown': critical reflection on a Clown Cabaret Scratch Night
}

\author{
LUCY AMSDEN
}

DOI: $10.14439 /$ sjop.2015.0202.02

Publication date: 26 June 2015

This article is a critical reflection on the Clown Cabaret Scratch Night at Assembly Roxy, 14 November 2014, organised by Plutôt la Vie and CloWnStePPing. It considers the variety of acts included in the show and how this plurality connects to the wider contemporary genre of theatre clown. From a participant-observer perspective, I introduce the tensions and contradictions in and between the acts. I suggest that this event can provide a snapshot of how the genre is currently perceived and practiced in Scotland today. Of particular prominence are the role of the 'flop' in the clown's relationship with the audience, the tension between rehearsal and spontaneity, and the connection to the 'authentic self' of the performer this implies.

Keywords: clown, performer training, rehearsal process, audience 


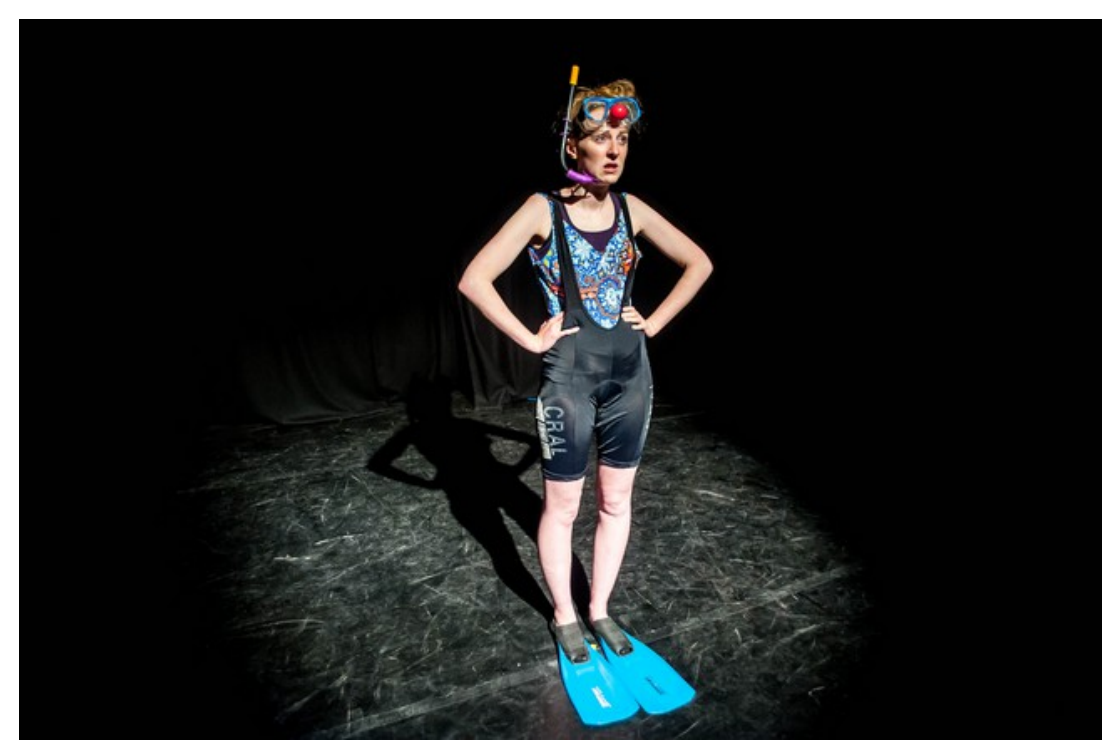

Figure 1: The author performing at the Clown Cabaret Scratch Night. All images by Mihaela Bodlovic.

I entered the stage, walking as normally as my flippers permitted, breathing through my snorkel and peering at the audience through steamed-up goggles. I stopped, smiled, turned my toes out neatly. They laughed. I shifted the goggles to my forehead, taking the red nose with them. 'I'm not really a clown', I told them, 'I'm a researcher'. They laughed again. During my act, I explained my journey from bad student at Gaulier's school to enthusiastic researcher, to exhausted and anxious postgraduate in the final stages of completing my thesis, and finally to intimidated but excited performer.

Held at Assembly Roxy in Edinburgh on 14 November 2014, this was the third Clown Cabaret Scratch Night organised by Plutôt la Vie and CloWnStePPing. These established companies organised the event as a "platform for established and emerging artists to experiment with ideas, and develop a wide variety of material with roots in a Theatre Clown audience relationship' (Plutôt la Vie, 2014, n.p.). The event was planned as a space where practitioners could develop work in this genre, there being no other such opportunity in Scotland outside the Edinburgh Festival Fringe. The purpose of the event was multiple: to give performers the opportunity to develop clown scenes with 
guidance from experienced practitioners and 'essential live audience feedback', to bring practitioners together to build a community for collaboration and the chance to see each other's work, and finally to 'broaden the audience's expectation of clown' (Licata and Feijóo, 2014, n.p.). This specialist scratch night provides a snapshot of the genre as it emerges in Scotland. I will document the event from my perspective as a participant-observer, and provide critical reflection on the process and performance event. This experience was not practice-as-research, but rather an experiment with some ideas from my theoretical and practical exploration of clown at École Philippe Gaulier. I sought to experience the role of clown, which I define as 'playing with the intention of making the audience laugh' (Amsden, 2015, p.59). I hoped to describe or even share my research in the context of a clown act, comically professing my non-adherence to the role while enacting some clowning skill. I also watched most of the other acts during performance or rehearsal, allowing me to conduct analysis of selected performances. Following the event, I conducted an interview with two of the organisers in which we reflected on the event and the genre as they understand it. I also contacted performers by email to ask for their own reflections on the event, some of whom provided written responses.

The organisers refer to the practice explored in the scratch nights as 'Theatre Clown', and elsewhere as 'Contemporary Clown'. Acts were selected for inclusion by producer/practitioners who are primarily concerned with a playful and responsive audience relationship, most visible when the clown makes the audience laugh and responds to this laughter. Such practice has been influenced by the teaching of Jacques Lecoq (1921-1999) and Philippe Gaulier (b. 1942), both of whom have explored this traditionally popular form alongside mask, tragedy, melodrama and bouffon since the 1960s. Some of the participants of the scratch night have taken short courses with Gaulier, and a 
culture of workshops in physical theatre training allows the ideas of these teachers to percolate and shift as they are passed on. In their book on Lecoq and the British theatre, Chamberlain and Yarrow acknowledge that the proliferation of short workshops has meant that there exists a large network of practitioners in the UK 'who have worked with Lecoq graduates, knowingly or unknowingly, incorporated the exercises, methods and aesthetics into their own work and passed them on to others' (2000, p.2). In conversation and rehearsal, Licata acknowledged my own experience with Gaulier by explicitly evoking his keywords and principles, and during rehearsal another performer who trained at the school even gave himself feedback in what resembled an impression of Gaulier's voice. The event also included clown practices drawing on a range of practitioners diverging from this dominant paradigm. These include more circus-based acts that used tricks that went wrong (see Davison, 2013), and dramatic numbers that used the 'clownesque'- in which 'incongruous events...reflect a clown's logical (or illogical) view of the world' but encourage pathos as well as laughter (Peacock, 2009, p.106).

\section{The participants}

The show consisted of 11 acts by a total of 16 performers, 15 of whom are based in Scotland. It was organised by three experienced clown performers and directors: Tim Licata, Melanie Jordan and Saras Feijóo. Tim was a founding member of Plutôt la Vie in 2002 and works as a performer, director and teacher of theatre, including clown, bouffon and Feldenkrais. He is influenced by his experience studying with Gaulier and Monika Pagneux. He also works with Hearts and Minds, a charity that provides performance in hospitals and care settings. Melanie is a performer and director, has worked with Plutôt la Vie and was awarded a Fringe First Award for her show Sanitise at Underbelly in 
2014. Saras is a clown performer under the company name CloWnStePPing. She has trained and performed in a variety of contexts in Colombia, Venezuela and Europe.

The opening act had a dramatic structure, performed wordlessly with live cello accompaniment. It consisted of three performers with suits, bowler hats and white faces decorated with black shapes. The relationship between these individuals was elusive; the piece had a theme of memories, diaries and perhaps a more sinister surveillance, as one performer continually tried to catch out the other two as they shared cut-out shapes from notebooks. This was a new act performed by experienced cabaret act Creative Martyrs. The final act of the night was based on a magic act entitled 'El Fantastico and his glamorous assistant Luna Balloona': Fergus Dunnet and Suzie Ferguson performed a series of illusions that were either comical in their success (such as the apparent ingestion of an inflated modelling balloon), or in their failure (such as a levitation trick which had its mechanism revealed accidentally). Fergus and Suzie had previously performed this act regularly in street performance in Barcelona. These two acts had very different tones, the opening being wistful, intriguing and poetic, whereas the final act was more flamboyant and used comic violence to create high energy and laughter. 

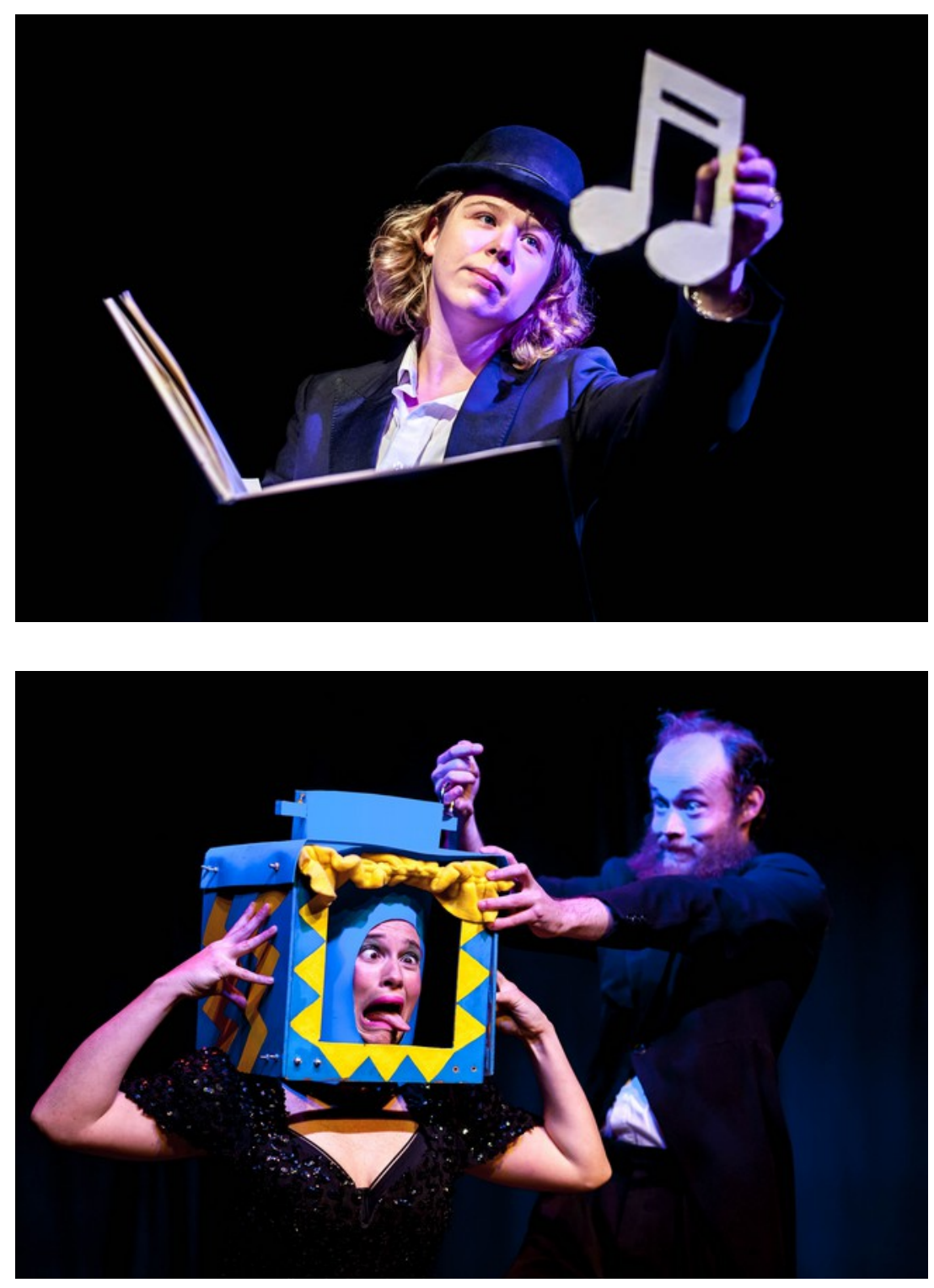

Figures 2 and 3: Creative Martyrs (above) and El Fantastico and Luna Balloona (below).

Circus and event performer DeLighters (Jusztina Hermann), performed a skilled hula hooping display, with one aspect that disrupted the professionalism of the performance- she tried to keep hold of her handbag. At first this led to awkward poses during particular tricks, but then she dropped the bag and had to stretch to pick it up while attempting to continue the routine. Then the soundtrack that accompanied her act ran out, and she signalled to the technician to play the track again while she finished the routine. This cabaret was a chance to continue working with an idea that had been developed with Angela de Castro at the SURGE festival of street arts, physical theatre and circus, in 
Glasgow 2011.

The Bare Hearts (Bec Phipps and Cat Somerville) also used this presentational mode, not creating a setting but acknowledging the fact they were on stage. They entered the stage as cleaners, but on noticing the audience performed a series of dances. This act used a similar premise to that of Jusztina, the dancing changed and there were mishaps with props, but still the dance continued.
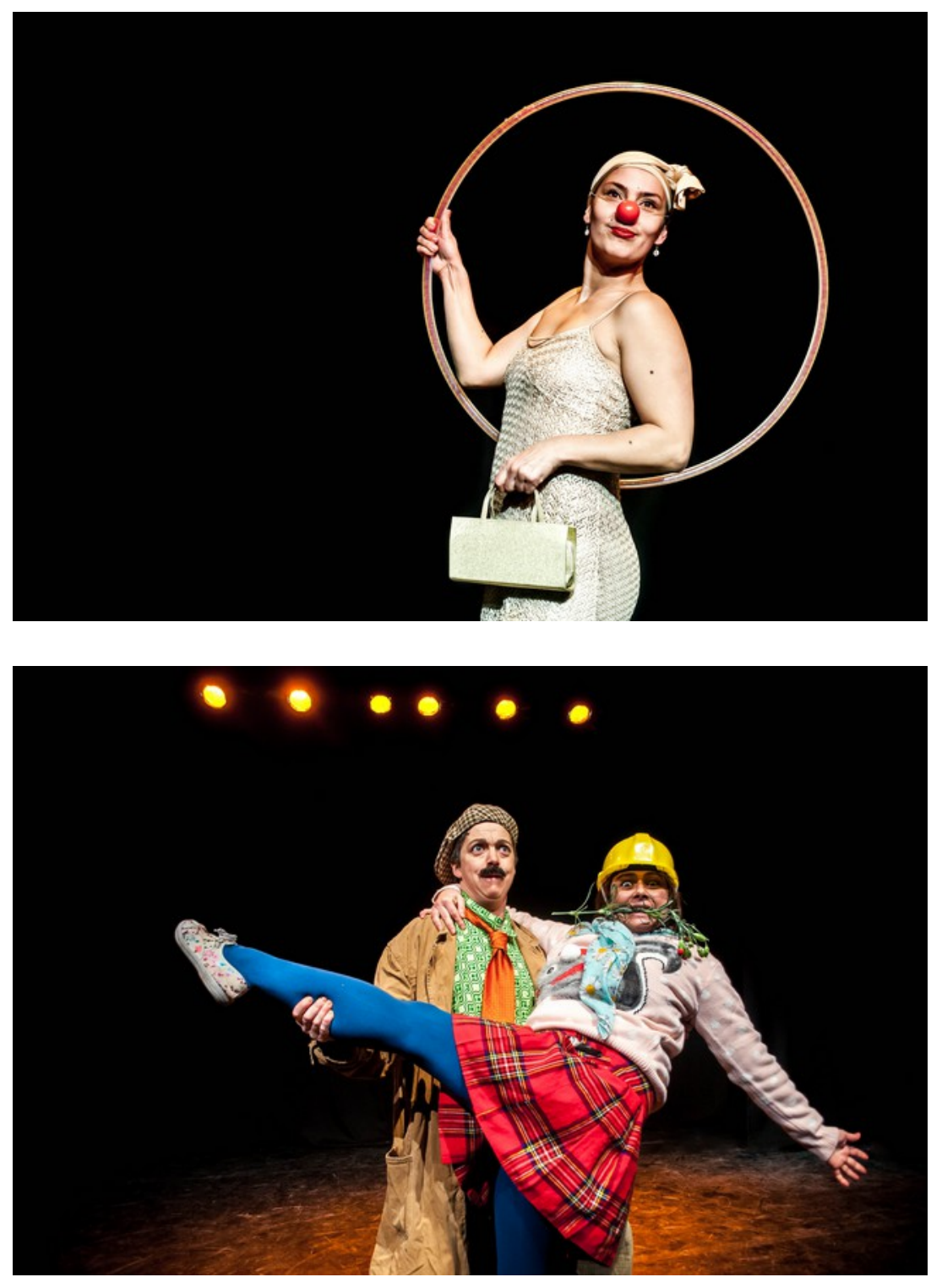

Figures 4 and 5: DeLighters (above) and the Bare Hearts (below).

Marcus Roche introduced and then impersonated a French 
economics specialist, positioning the audience as his seminar attendees. In a similar vein, Ronan McMahon reimagined the stage as a 'serious' performance space of a silent lecture on complex number theory, illustrated on a blackboard. These two acts played with the difficulty of explaining or presenting, and both used high-status clown persona undermined by the concept he was trying to explain.
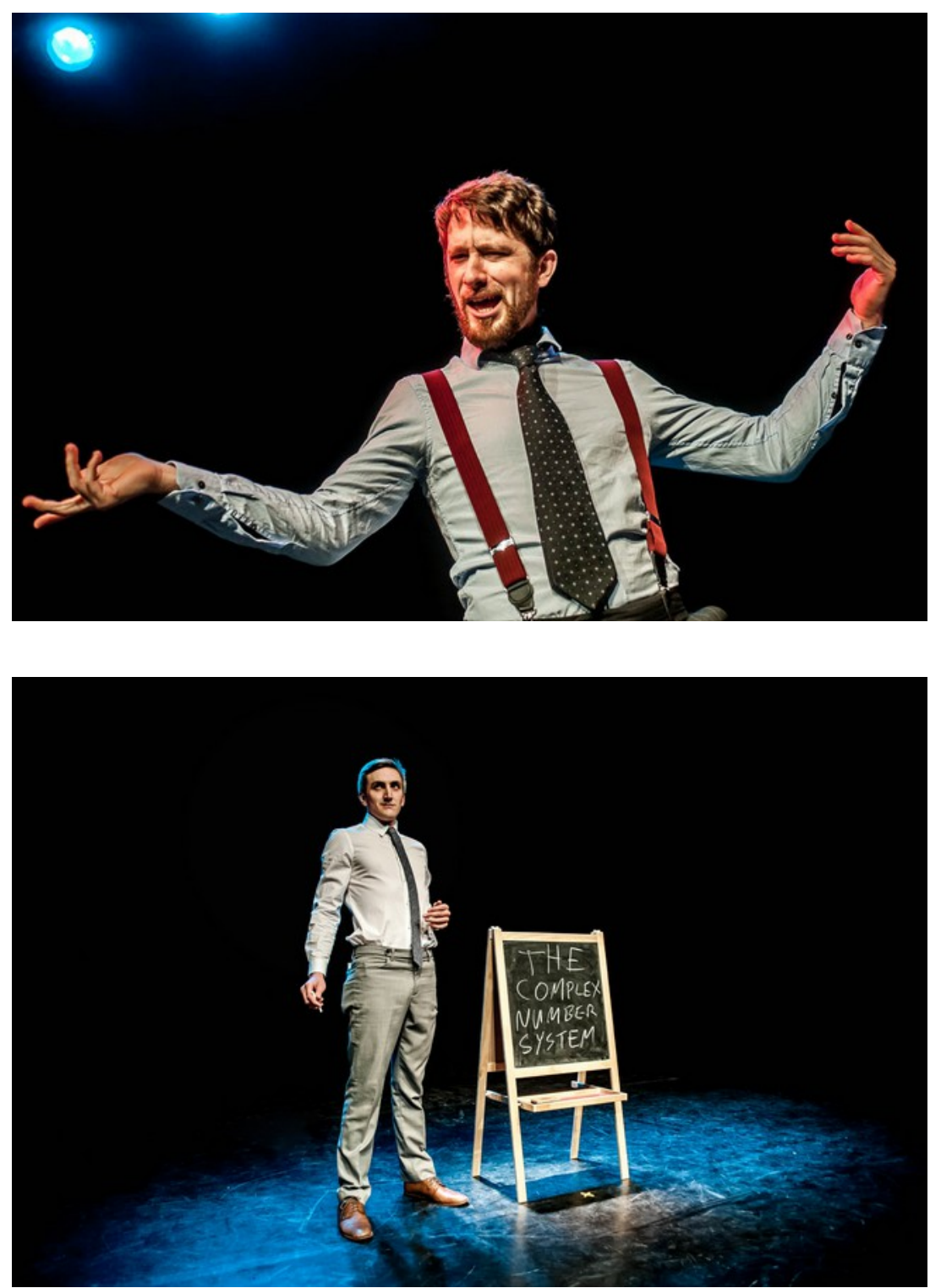

Figures 6 and 7: Marcus Roche (above) and Ronan McMahon (below).

Andrew Simpson's act documented a real, difficult experience. Using physical interaction with the audience, he 
discussed an intimate moment from his personal life and explored discomfort in the form and content of his act. Like Andrew, Lucy McGreal confronted romance in her scene. She invited a member of the audience to join her for a blind date on the stage. The audience participation in this act asked a lot of the volunteer chosen, as Lucy invited him onstage and then stared at him, as though waiting for him to speak. At the end of the scene she serenaded her date with the John Legend song All of me, accompanied on the ukulele. Tim, who introduced the night, also appeared in this scene as a waiter involved in a final plot twist.
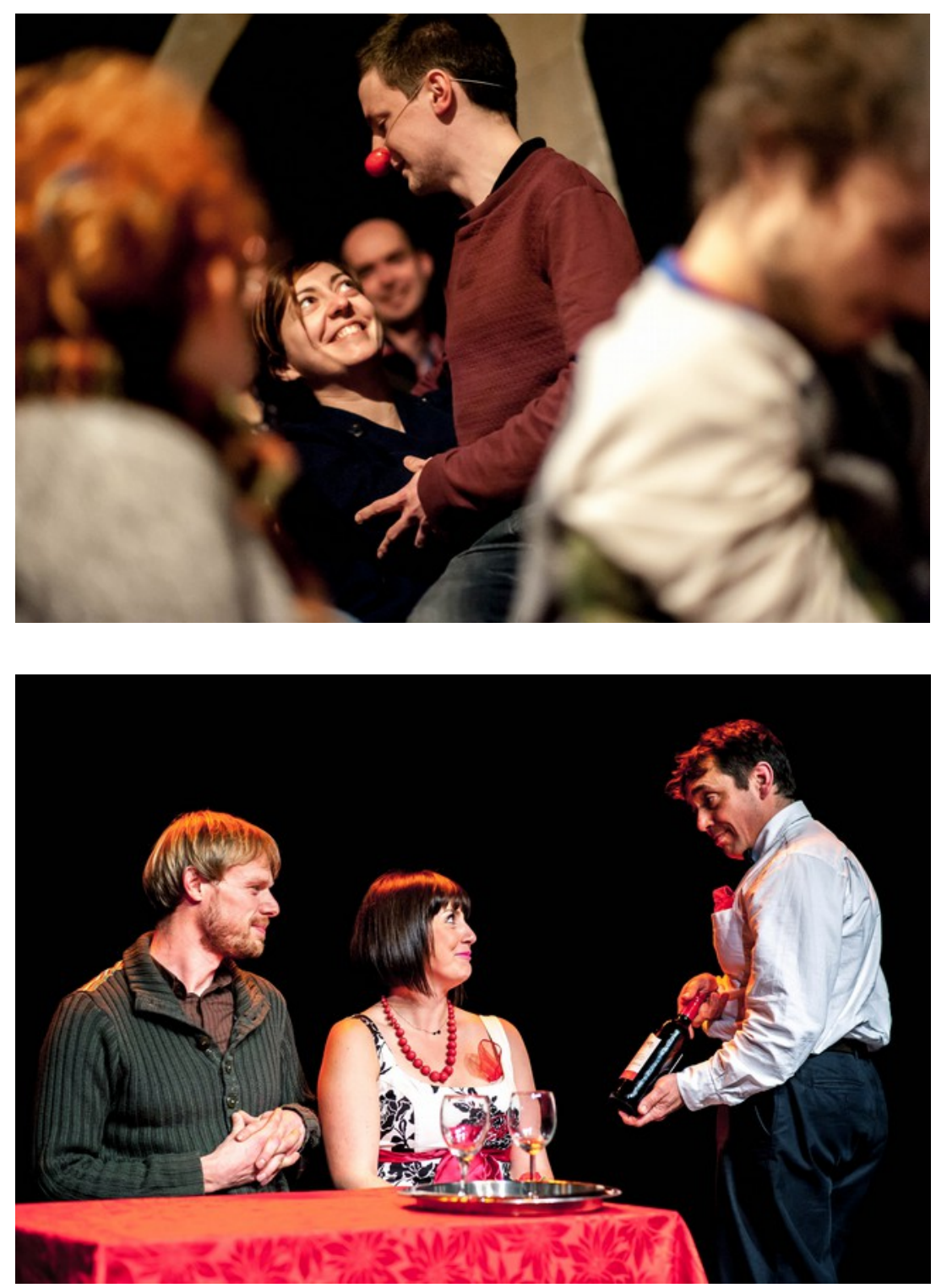

Figures 8 and 9: Andrew Simpson (above) and Lucy McGreal (below). 
The remaining two acts were excerpts from longer shows currently in development and both used comedy and pathos to deal with emotional themes, presented with fictional or dramatic settings. Saras presented a section from her show Blooming Surprise, in which she was alone and looking for company in an airport. Aron de Casmaker presented a scene from his show, Entrenched, about the life of soldiers in the Second World War. Aron used a single word- 'Sauerkraut'and costume to depict a German soldier. He threw balls of paper into the audience, playfully asking individuals to make the sound of their impact, but then ended the piece with projected images of real warfare. These scenes both sought to contrast different types of emotion, and included quiet and sombre moments as well as laughter.

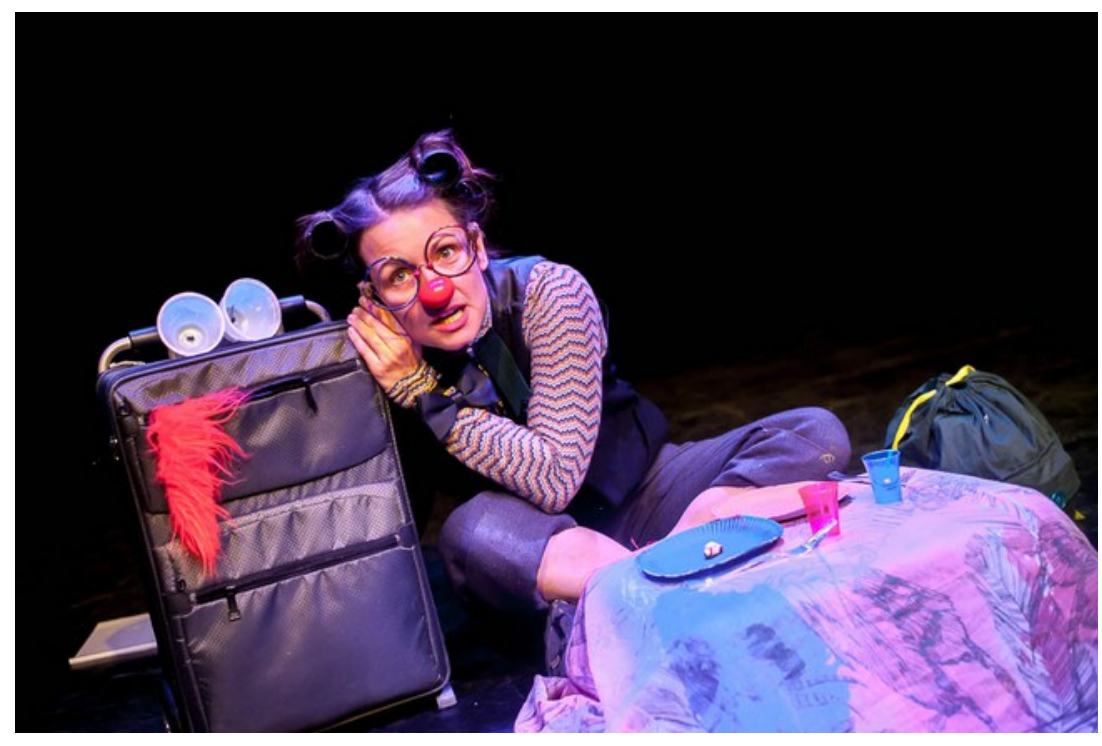

Figure 10: Saras Feijóo. 


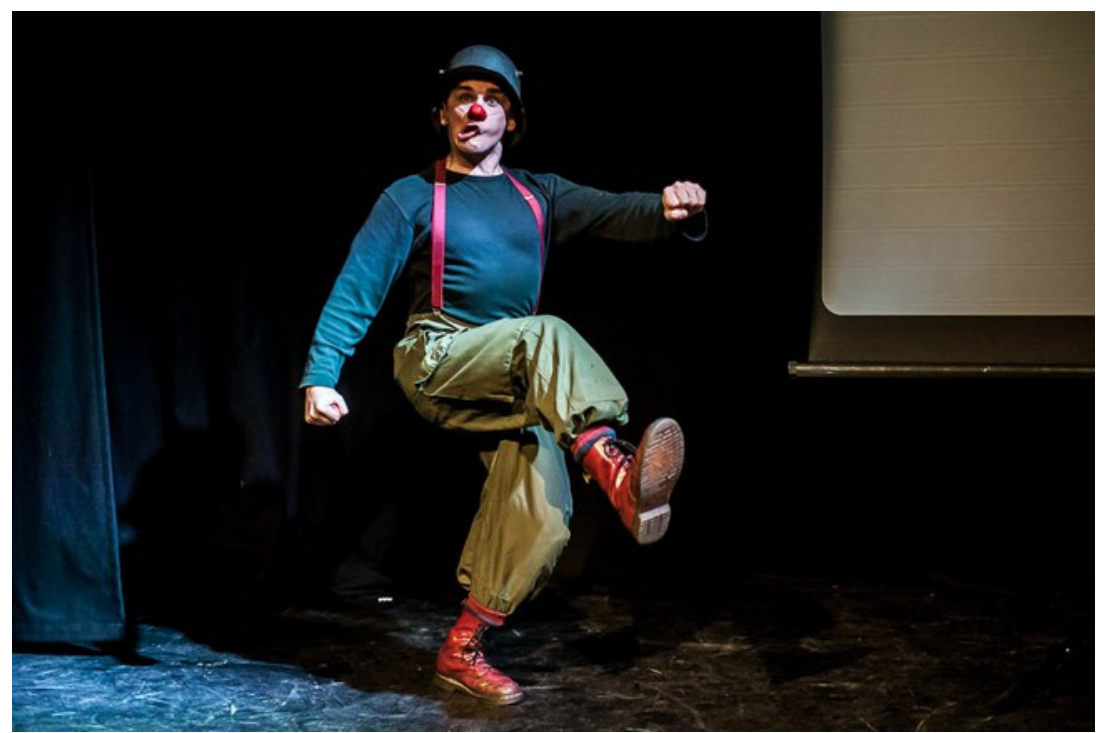

Figure 11: Aron de Casmaker

The performers were eight women and eight men, although one woman was in drag, wearing a moustache. In this context, clown is not the predominantly male practice described by Peacock (2009). Five performers wore plastic red noses, while the remaining performers had their faces bare, and the colourful face paint associated with the American circus (Auguste) tradition did not appear. Costumes varied between smart, tatty, and bright or surreal clothes. There was little reference to 'classic' clown acts (see Rémy, 1945; Towsen, 1976), and very little slapstick, or comic violence (see Peacock, 2014). Not all of the acts seemed to prioritise making the audience laugh, suggesting a possible shift from Gaulier's definition of successful clowning which does focus on the audience's laughter: 'the work of a clown is to make the audience burst out laughing' (Gaulier, 2007, p.289). If judged according to a Gaulier-based definition of clowning, there were varying levels of clown success, as measured by different levels of audience laughter. Overall, there was a lot of laughter in response to the scratch night, but the acts demonstrated a variety of approaches to the genre of clown, with narrative and pathos being significant in some moments, so measuring laughter would not be the most productive evaluation of the event. Furthermore, because of the developmental aspect of the show, the acts varied in how 'finished' they were, or how successful 
according to their own definitions. It is interesting to trace themes across the clown material that made up the acts, including difficult or awkward interactions, fun actions somehow going wrong, and frightening or emotional situations juxtaposed with comedy. A question that emerged in several acts and my own participation was how the clown can be understood as personal, an idea that connects with the plurality created by the show overall.

\section{Personal clowning}

The organisers deliberately sought a diverse range of acts, stating in their call for participants:

If you have a short piece or an idea for a piece that you would like to develop- we would like to hear from you! With or without a red nose, the evening is open to your interpretation of Clown. Masks, slapstick, silence, movement, magic, juggling, circus, poetic clown, new vaudeville... No holds barred! Everything is welcome (Feijóo, 2014, n.p.).

Nonetheless, the content of the event reflects a certain understanding of clown, primarily because a playful relationship with the audience was a definitive feature of the genre for the organisers. Tim, Melanie and Saras selected acts at several stages: application, audition and development, and at these stages they sought:

A certain kind of relationship with the audience, which can be very broad [...] I think we wanted to open that out to see what other interpretations of clown might come in or might be brought in (Licata, 2014, n.p.).

The organisers assessed performances for suitability by 
application and audition, choosing only pieces that demonstrated an interest in connecting with the audience. This was taken more literally by Lucy, Andrew and Aron, who singled out individuals and invited them to join in the performance. However, all performers adhered to this definition of clown because they acknowledged the presence of the audience with eye contact and/or reactions to laughter when it occurred. A stated interest in a broad and fluid interpretation of the genre was shadowed by a shared definition of the boundaries of an extant if non-mainstream practice.

Variation according to personal inclination, skill and preference is an intrinsic part of the genre as imagined by Gaulier and Lecoq. This contains the paradox of the selection process. Saras explained her own application of this idea:

everyone has their own way to interpret clown, because we are different, and clown is [...] from what we are, in some way, so that's where the diversity will be based, in my opinion (Feijóo, 2014, n.p.).

Performers also associated themselves with their material, and when asked how this event would influence them in future, individuals described a continually changing practice. Jusztina spoke of her clown as a persona who she had 'enjoyed developing and making friends with', as though the clown existed in some way independently of herself (Hermann, 2015, n.p.). Aron described himself as 'the performer who walks on stage open to the reaction to the audience. As a clown performer, I hope this will always mean I change' (de Casmaker, 2014, n.p.). Similarly, Suzie answered that her clowning 'is changing and developing all the time. Just like I am' (Ferguson, 2014, n.p.). Andrew told me that the slow, awkward feeling in his piece was his tactic to connect with the audience- 'it was important for me that 
it was very closely linked to my real life, uncomfortably so'so that this authentic discomfort could be shared honestly (Simpson, 2015, n.p.). Peacock (2009) describes a contemporary understanding of proximity between clown performance and the performer who devises it:

When a clown performs, the audience see the ideas and attitude of that individual conveyed by an adopted persona that has developed out of the individual's personality and which could never be adopted and lived in the same way by anyone else (p.14).

These practitioners in Scotland, in various ways, adhere to the notion of clown as inherently connected to the performer.

Clown practitioner, teacher and writer Jon Davison critiques a 'clown orthodoxy' that seeks sincerity, spontaneity and 'inner authenticity' (Davison, 2013, p.198). He suggests that there is a common misunderstanding that the appearance of failure in clown acts necessarily means the act is spontaneous and the clown's performance is sincere or connected to the performers self. This criticism is based on the realisation that although clown students experience real failure in the clown classroom, failures in clown performance can be, and often are, acted.

We can accept [...] failure in full view of an audience, who will see everything as long as the performer lets them. This creates an effect, for the audience and the performer, that something that is usually hidden is being revealed (2013, p.199).

This complex discussion was played out in the acts of the Clown Cabaret Scratch Night. Many mistakes in the skillbased acts were deliberately created for comic effect, as 
were the awkward moments created by the presentations and the fictional mistakes depicted in the more dramatic acts. According to Davison's argument, it is the acknowledgement of the audience's audible or visible response to these (acted) failures that makes the clowns appear to reveal something authentic about themselveseven though the failures themselves were artificially created. He suggests that the appearance of authenticity in contemporary clown is thus a 'theatrical truth-effect' (ibid.). Laura Purcell Gates agrees that flops can be acted when she suggests that:

In a clown performance before an audience, it is a rehearsed mistake; in the clown classroom, it is genuine- the student truly messes up and faces a moment (often unbearable) of not knowing what to do next (2011, p.236).

Performers in this event did rehearse many of their mistakes, with Jusztina's dropped handbag being a clear example. The structure of this act meant that even though her mistake had been planned, dropping the bag gave her a physical problem to resolve, as she tried to continue spinning the hoop while stretching to pick up the bag. While Jusztina did know 'what to do next' because she had rehearsed the act, the reality of splitting her concentration between two tasks created the effect of a flop, handled honestly and imaginatively in real-time in front of the audience. It is perhaps the moment of reacting to a flop, whether it is rehearsed or a surprise to the performer, that brings the question of authenticity into the audience experience. I laughed when Jusztina dropped and tried to regain her bag in the performance, despite having seen the same actions in the technical rehearsal a few hours before. Despite expecting this moment, her admission of the problem and difficulty of performing the two actions still made me laugh. 


\section{Development}

While scratch nights provide audience feedback, and a selection process offers some opportunity for critique from experienced practitioners, this event laid particular emphasis on development for the participants. My audition involved presenting an idea for the act and then being directed and provoked to improvise further material. This interaction was familiar to me from clown workshops and at times provoked me to feel moments of 'not knowing what to do next' described by Purcell Gates. The same structure was used and the process continued in a 'development day', two hours of rehearsal with Tim, Saras and Melanie. This was an attraction for participants including myself, and seven of the acts took this opportunity for rehearsal and advice.

Given the timing of the audition, towards the deadline of my PhD submission, I was in an anxious frame of mind. I had written a joke in which I boasted of being 'Scotland's top clown researcher', and then admitted that I don't know of anybody else in the country studying this subject. Tim suggested I repeat this statement, but with more humility, and none of the bravado. He then asked for details about the amount of time I had spent on my thesis. His next instruction was to silently ask myself 'why?'. Tim, Saras and Melanie laughed as I reflected on this question, and although in other situations I might have been defensive, I was complicit in this laughter. As a result, the act I developed directly referred to my research experience rather than my findings. This changed my role from theoretical 'expert' to ridiculous student and practical beginner, making me to some extent 'wrong' in the context of the show (Davison, 2013, p.131). My quest to be taken seriously matched those tasks of other performers- it was a task destined to be undermined, and as such worked in the same way as Ronan's complex number theory lecture, Jusztina's hula hoop routine and Bec and Cat's dance. After deciding to use this humble attitude towards my research, I used the development day to identify actions or ideas that 
made the directors laugh and then found ways of repeating these and changing them. I explicitly played a game with the audience, explaining how the game worked and their role in it: I could take a step forward when 'they liked me', which I measured by smiles and laughter, but had to step back when they were unamused. In doing so I referred to Gaulier's term 'the flop', saying that I was there to discover 'what it's like when the audience don't laugh'. We watched each other, waiting. I heard that they were not laughing, and nodded '... Huh' as I stepped back. This game, which I learned with Gaulier, has also been developed by Davison, who explains that '[i]nterestingly, these steps back often generate the biggest laughs. Why? Because they are admissions of failure' (2013, p.291). As I had hoped, and as suggested by Davison, this acknowledgement of my flop did get one of the biggest laughs of my performance, and because I had explained the game, the audience went on to generously clap and cheer as I moved forward. This moment of my piece was developed in the rehearsal but depended on some skills of responsive timing, a dichotomy that was visible in a number of the acts.

\section{Fixity and flexibility}

While the organisers sought performers who were responsive to the audience, we all presented sketches which were 'written' in the sense that we knew we would perform certain actions, words and/or narratives. By the end of my development session, Tim gave me some very specific direction concerning timing that I used in the performance. It broke up my entrance into a series of distinct actions. These were described, approximately as follows: 'You come in, nervous and excited. Then there's a beat. You move the flippers. Beat, then a smile'. In performance, there was a laugh during each 'beat' described above, and I believe the beats lasted longer than they had done in the technical rehearsal, because I did not do the next action until the 
laugh had subsided. The actual timing was not fixed, but the rhythm was, and this responsive skill appears to be a definitive element of clown practice according to this event.

During my development day, I was encouraged to slow down and give time for audience laughter, which was explained in terms of personal revelation with the phrase 'give us space to see you'. Melanie mentioned that this feedback had been relevant to other performers as well. However, following the show, the organisers agreed that in future they will give feedback to performers about something just as importantnoticing 'when you're losing the audience and when it's time to move on' (Licata, 2014, n.p.). In future scratch nights the organisers intend to develop their 'curatorial' role, making sure to have development time with every participant, and being strict about timing on the night. Saras hopes that this will have an impact on the quality of the audience experience:

I think this structure helps you to deliver something that makes sense to the audience. Because otherwise it will be this 'oh yes I am a clown, I go on the stage I do everything that I want, because I'm a clown', but then you are wasting the time of the audience, and their energy (Feijóo, 2014, n.p.).

With more responsibility to the other performers, and attention given to the audience's disapproval as well as their approval, the show would maintain its ambiguities yet be more coherent and enjoyable.

The other performers whose technical rehearsals I observed were able to detail the actions of their scene fairly specifically, but with some flexibility in timing. Lucy and Andrew planned to use audience volunteers, so in the technical rehearsal they were only able to estimate what 
would happen but could still provide details of actions they planned to perform at some point. Licata described this phenomenon as 'a lovely paradox' in clown dramaturgy:

[i]n a sense, you need to know what you're doing, and it needs to be very free, and so there's this paradox of being kind of structured chaos, those two things are there (2014, n.p.).

This 'lovely paradox' is parallel to a closely related dichotomy, also discussed in the development day, between the clown being improvised or responsive and the structured, repeatable act. Tim also referred to this as a 'dance between technique and life', where a delicate balance must be struck between reliable performance skills (such as being audible, timing and structure) on one hand, and a genuine connection with the audience on the other (2014, n.p.).

In my own performance, I found a very ambivalent position regarding the truth. Like Andrew, I took the idea of clownas-personal literally, and so presented spoken content referring directly to my life off-stage. A section of my material consisted of three short stories of critical feedback I had received from Gaulier while participating in his Clown course (2009). The first is true; he stopped me as I stood on stage and asked 'why do you move from side to side like a penguin with bowel problems?' This was a comic, cutting and precise observation of a bad habit, which I now notice every time I am on stage. The second two stories capture the way I felt when leaving the school, but are somewhat embellished. The events in the story did happen while I was at the school but to other students. These had both the comic effect and communicated a truthful emotion, even though they were in some sense acted, or Davison's 'theatrical truth-effect'. Another layer was added to this 'dance' of technique and life, because after the show several people asked me if I really was a researcher, and if I really was 
writing this article, or if that had just been a joke. The audience members wanted verification of my spoken content, suggesting that the authenticity of acts was also of interest to the audience.

\section{Conclusion}

The clowns were smart, scruffy, masked, unmasked, clever, stupid, skilled, confident and awkward. Their acts were silent, spoken, fictional, presentational, funny and sad. In several performances, there were tensions between the real and fake, generic tradition and personal revelation, the rehearsed and the improvised. My own experience and the accounts of other practitioners involved suggests that these tensions are significant to clown practice as it exists in this context. Plurality in the show, created by the fluidity of the genre's boundaries, also connects this practice to the teaching of Gaulier, Lecoq and a widening network of practitioners developing from this paradigm. The cabaret structure and development pattern fits a workshop-based training structure by allowing for ongoing learning, variation, and contradiction within the genre. This performance structure is suitable for clowning because it presents a varied sample of different practices, and in this snapshot of Scottish clown practice, ambiguity abounds.

Furthermore, the organisers' interest in the clown's relationship with the audience meant that the question of authenticity circulated in rehearsal and performance. Though the event was curated by audition and the acts rehearsed to technical detail, the fact this event is called a scratch night means that all the material is framed as undergoing development. The value placed on responsiveness to the audience suggests that an element of unpredictability and willingness to experiment and improve acts is also prized in Scottish clown practice. 


\section{References}

Amsden, L., 2015. ' The work of a clown is to make the audience burst out laughing’: Learning clown at École Philippe Gaulier, $\mathrm{PhD}$, University of Glasgow.

Chamberlain, F., and Yarrow, R., eds., 2000. Jacques Lecoq and the British theatre. Abingdon: Marston.

CloWnStePPinG, 2015. [online] Available at:

〈http://www.clownstepping.com〉 [Accessed 8 January 2015].

De Casmaker, A., 2014. Re: Some Clown Questions. [email] (personal communication, 12 December 2014).

Davison, J., 2013. Clown. Basingstoke: Palgrave Macmillan.

Ferguson, S., 2014. Re: Some Clown Questions. [Email] (personal communication, 10 December 2015).

Feijóo, S., 2014. 'Autumn Clown Cabaret Scratch Night Call out!!!!' 5 August 2014. Creative Adventure. Available at:

〈https://sarasfeijoo.wordpress.com $\rangle$ [Accessed 8 January 2015].

Gaulier, P., 2007. Le gégèneur: jeux, lumière, théâtre/The tormentor: le jeu, light, theatre. Translated by E. Maclachian. London: Éditions FILMIKO.

Hearts and Minds, 2013. [online] Available at: 〈http://www.heartsminds.org.uk $\rangle$ [Accessed 8 January 2015].

Hermann, J., 2015. Re: Some Clown Questions. [email] (personal communication, 6 January 2015).

Jordan, M., n.d. [online] Available at: 〈http://melaniejordan.weebly.com $>$ [Accessed 8 January 2015].

Licata, T. and Feijóo, S., 2014. Interview with the author. [interview] (personal communication, 25 November 2014).

Murray, S. and Keefe, J., 2007. Physical theatres: a critical introduction. London: Routledge. 
Scottish Journal of Performance

Volume 2, Issue 2

Peacock, L., 2009. Serious play. Bristol: Intellect.

Peacock, L., 2014. Slapstick and comic performance; comedy and pain. Basingstoke: Palgrave Macmillan.

Plutôt la Vie, 2010. [online] Available at:

〈http://plutotlavie.org.uk/about/〉 [Accessed 8 January 2015].

Plutôt la Vie, 2014. Application form for Quality Production: project development. Unpublished.

Purcell Gates, L., 2011. Locating the self: narratives and practices of authenticity in French clown training. Theatre, Dance and Performance Training, 2(2), pp.231-42.

Rémy, T., 1945. Les clowns. Paris: Grasset.

Simpson, A. 2015. Re: Some Clown Questions. [Email] (personal communication, 6 January 2015).

Towsen, J.H., 1976. Clowns. New York, NY: Hawthorn Books, Inc.

\section{About the author}

LUCY AMSDEN has recently completed a PhD at the University of Glasgow, entitled 'The work of the clown is to make the audience burst out laughing': learning clown at École Philippe Gaulier. She has presented research nationally, and performed in Bright Club at The Stand, Glasgow and Edinburgh. 